Article

\title{
Synthesis of Graphene Oxide Based Sponges and Their Study as Sorbents for Sample Preparation of Cow Milk Prior to HPLC Determination of Sulfonamides
}

\author{
Martha Maggira ${ }^{1}$, Eleni A. Deliyanni ${ }^{2}$ (i) and Victoria F. Samanidou ${ }^{2, *}$ (]) \\ 1 Laboratory of Analytical Chemistry, Department of Chemistry, Aristotle University of Thessaloniki, \\ GR-541 24 Thessaloniki, Greece; marthamaggira@gmail.com \\ 2 Laboratory of General and Environmental Technology, Department of Chemistry, Aristotle University \\ of Thessaloniki, GR-541 24 Thessaloniki, Greece; lenadj@chem.auth.gr \\ * Correspondence: samanidu@chem.auth.gr; Tel.: +30-2310997698; Fax: +30-2310997719
}

Received: 8 May 2019; Accepted: 31 May 2019; Published: 31 May 2019

\begin{abstract}
In the present study, a novel, simple, and fast sample preparation technique is described for the determination of four sulfonamides (SAs), namely Sulfathiazole (STZ), sulfamethizole (SMT), sulfadiazine (SDZ), and sulfanilamide (SN) in cow milk prior to HPLC. This method takes advantage of a novel material that combines the extractive properties of graphene oxide (GO) and the known properties of common polyurethane sponge (PU) and that makes sample preparation easy, fast, cheap and efficient. The PU-GO sponge was prepared by an easy and fast procedure and was characterized with FTIR spectroscopy. After the preparation of the sorbent material, a specific extraction protocol was optimized and combined with HPLC-UV determination could be applied for the sensitive analysis of trace SAs in milk. The proposed method showed good linearity while the coefficients of determination $\left(R^{2}\right)$ were found to be high (0.991-0.998). Accuracy observed was within the range 90.2-112.1\% and precision was less than $12.5 \%$. Limit of quantification for all analytes in milk was $50 \mu \mathrm{g} \mathrm{kg}^{-1}$. Furthermore, the PU-GO sponge as sorbent material offered a very clean extract, since no matrix effect was observed.
\end{abstract}

Keywords: sulfonamides; HPLC; graphene oxide; sponge; milk

\section{Introduction}

Sulfonamides are a group of synthetic antibacterial agents, which are widely used in veterinary practice for prophylactic and therapeutic purposes and as feed additives. Due to their ability to inhibit folic acid synthesis in microorganisms, they are commonly used against a wide range of bacteria, protozoa, parasites, and fungi [1-3].

However, the improper administration of sulfa drugs in dairy husbandry and the insufficient withdrawal periods can lead to noncompliant residues in animal originated foods, a fact which can contribute to several concerns in the dairy industry and public health [4].

In humans, such concerns comprise the rise of allergic or toxic reactions and the development of drug-resistance, whereas in the dairy industry they provoke the inhibition of bacterial fermentation in cheese and yoghurt production [5]. In order to safeguard public health and ensure food safety, monitoring of such residues in products designated for human consumption is considered mandatory. For this reason, the European Union has established a maximum residue level (MRL) for sulfonamides in foodstuffs of animal origin, which in the case of milk is $100 \mu \mathrm{g} \mathrm{kg}^{-1}$ [6] 
Additionally, several methods have been described for the detection and/or determination of sulfonamides in foods of animal origin such as microbial inhibition assays, immunochemical methods, capillary electrophoresis (CE), gas chromatography (GC), and HPLC [5,7].

Sample preparation is a key step prior to the detection of sulfonamides present in different kinds of samples. The clean-up procedure of various matrices can be accomplished by either traditional techniques, such as liquid-liquid extraction (LLE) [8], or modern methods, like solid phase extraction (SPE) [9], solid phase micro extraction (SPME) [1,10], fabric phase solid extraction [11], matrix solid phase dispersion (MSPD) [12] and Quick, Easy, Cheap, Effective, Rugged and Safe (QuEChERS) method $[13,14]$. Most of the aforementioned techniques depend on an absorbent material to achieve high analytical specificity and selectivity.

However, in the analysis of complex matrices, many innovative materials have emerged as valuable tools to enhance the efficiency of the extraction and isolation of the target analytes. As such, graphene-based materials are preferred to other carbon-based nanomaterials due to their great potential on the sample preparation procedure. Graphene $(G)$ is a two dimensional nanomaterial with extraordinary physicochemical properties such as thermal and chemical stability, thermal conductivity, hydrophobicity, and large specific surface area [15]. Graphene oxide (GO) is a single-atomic layered material, an important derivative of graphene with similar structure, which is composed easily from the oxidation of graphite. However, GO is more polar than G because of the hydroxyl $(-\mathrm{OH})$ and carboxyl (-COOH) groups, a characteristic that facilitates $\mathrm{GO}$ bonds into other compounds such as aminopropyl silica [16].

Graphene based materials are extensively applied in SPE procedure as they offer high sorption efficiency for organic compounds and metal ions mainly in environmental samples [17-19]. Although G and GO demonstrate excellent sorbent characteristics, many limitations have been reported concerning their isolation from well dispersed solutions and their sheets' restacking or escaping from the SPE column $[20,21]$.

In order to surpass the problems having occurred during the elution and sample loading in SPE, new sample preparation techniques have been developed such as the use of graphene-based materials in dispersive solid phase extraction (DSPE) and MSPD. In DSPE the absorbent is mainly utilized in food [22] and environmental samples [23-26], whereas MSPD has been performed for the extraction of sulfonamides in milk samples [27].

Recently, melamine sponge was functionalized with graphene, via a microwave-assisted hydrothermal process, in order to be used as adsorbent for SAs extraction from milk, egg, and environmental water [28]. The proposed method was highly accurate and sensitive for the analysis of nine SA's. However, it is not referred to the determination of sulfathiazole (STZ), sulfamethizole (SMT), and sulfanilamide (SN). In the current study, commercial polyurethane (PU) sponges, a kind of cheap porous material, were examined for SAs extraction from milk. PU sponges, compared with other sponge materials, such as melamine [29,30], and chitosan sponge [31] present certain advantages like easy access, low cost, and high resilience, excellent flexibility, and reuse [32]. Moreover, the surface of the PU sponge was used as a skeleton for hydrophobic modifiers. Hence, in the current study, surface modification was achieved via a green route at ambient conditions.

Polyurethane (PU) sponges with a unique 3D structure have a potential application as absorbents due to their advantages of easy access, low cost, and high resilience compared to other porous materials, such as melamine foam and chitosan sponge. Although PU sponge is hydrophilic, modifications or physical coating like functionalization with graphene are required to increase the hydrophobicity and are usually used to achieve higher efficiency in separations [32].

Consequently, the objective of this study was to combine the unique properties of PU sponge being functionalized with GO in order to serve as an innovative absorbent material in the sample preparation procedures. Due to its properties of low cost, time saving, and simplicity, the GO-PU material was further used for the determination of sulfonamides in cow milk samples prior to HPLC-DAD method. 


\section{Results and Discussion}

\subsection{Characterization}

Polyurethane sponge was used as a base material in order to be functionalized with graphene oxide. Polyurethane presents an open-hole structure, with a high porosity as well as a rich surface chemistry with surface-groups that can attract and react with different molecules. Graphene oxide was embodied in the PU skeleton after the dispersion of GO in water. Graphene oxide was connected to polyurethane after chemical interactions between the GO (epoxy-groups) and polyurethane surface groups ( $\mathrm{C}=\mathrm{O}$ and $-\mathrm{N}-\mathrm{H}$ groups). After the polyurethane functionalization with graphene oxide, the sponge prepared appeared with a black color and presented hydrophobicity that was further increased after the coating with PVA.

The XRD diffraction patterns of the prepared graphite oxide (GO) as well as of the GO impregnated sponge before (PU-GO) and after the PVA coating (PU-GO-PVA) are presented in Figure 1. Graphite presents a sharp diffraction peak at $26.6^{\circ}$ in the XRD pattern (not presented), attributed to interlayer (002) spacing $(\mathrm{d}=0.33 \mathrm{~nm})$. The characteristic XRD peak of graphite oxide appeared at $2 \theta=10.9^{\circ}$; as estimated by the Bragg's law, the interlayer distance between the carbon layers, increased from $0.33 \mathrm{~nm}$ for graphite to $0.81 \mathrm{~nm}$ for GO [33]. In the XRD pattern of the GO impregnated sponge (PU-GO) the characteristic XRD peak of graphite oxide, at $2 \theta=10.9^{\circ}$, was not present, indicating that the layered structure of GO was destroyed. A diffraction peak at $2 \theta=21^{\circ}$ could be due to PVA while the broad peaks at around $11.6^{\circ}$ and $19.8^{\circ}$ indicated some degree of crystallinity of the PU [34-36]. The XRD pattern for the sample after the sulfonamide adsorption (PU-GO-SA), which is also presented in Figure 2, reveals that a decrease of crystallinity was observed, evidenced by the disappearance of the peak at $2 \theta=11.6^{\circ}$.

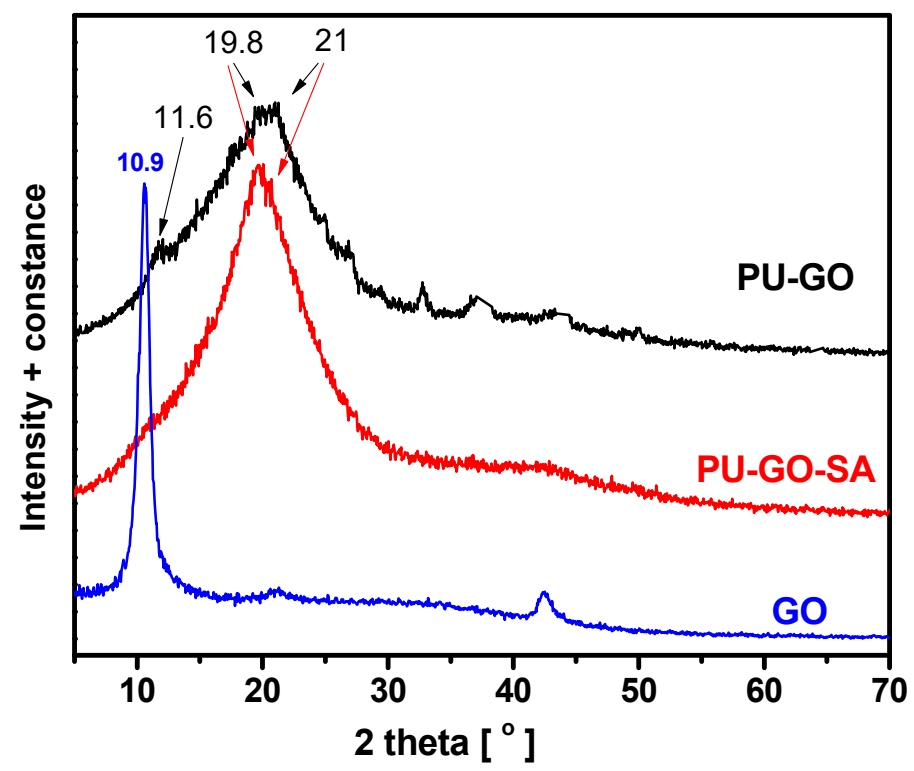

Figure 1. X-ray diffraction (XRD) patterns of the graphite oxide (GO), the graphene oxide impregnated sponge (PU-GO), and the sponge after the adsorption of sulfonamides (PU-GO-SA). 

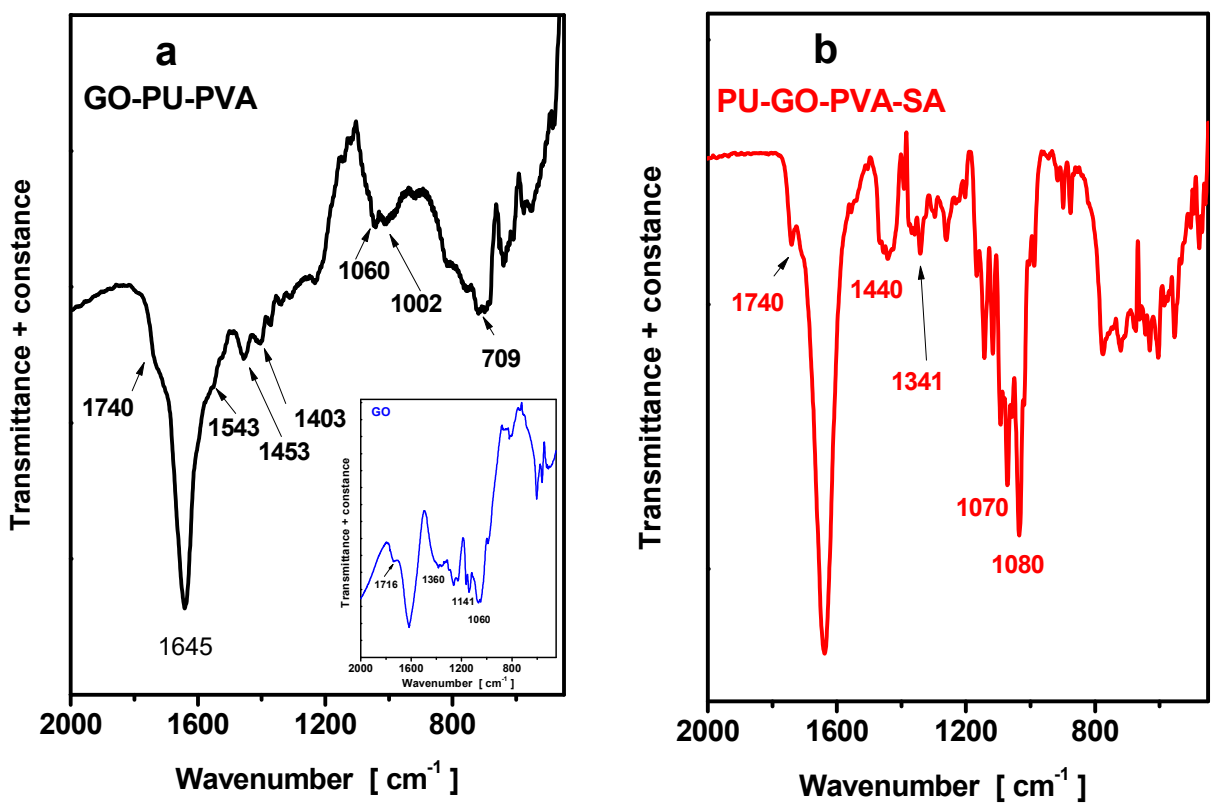

Figure 2. Fourier-transform infrared (FTIR) spectra for (a) polyurethane-graphene oxide- polyvinyl alcohol (PU-GO-PVA) sponge raw and after (b) the absorption of sulfonamide's (SA's) (PU-GOPVA-SA)-(in the inset the spectrum of GO).

FTIR spectroscopy was used in this study to identify the possible interactions between GO and PU (PU-GO), between PU-GO and PVA (PU-GO-PVA sponge) as well as between the sponge and the sulfonamides (PU-GO-PVA-SA) in order for the adsorption mechanism to be revealed. The FTIR spectra of PU-GO-PVA as well as of PU-GO-PVA after the sorption of sulfonamide (PU-GO-PVA-SA), are presented in Figure 2. The FTIR spectra of GO is presented in the inset of Figure 2. GO contains polar groups on the edges of graphite layers such as carbonyl, carboxyl, and epoxide, as well as hydroxyl groups within the basal planes of the graphene sheets. In the spectrum of GO (Figure 2a), the bands at 1050-1100 $\mathrm{cm}^{-1}$ and $~ 1716 \mathrm{~cm}^{-1}$ can be attributed to carboxylic groups whereas the band at $\sim 1600 \mathrm{~cm}^{-1}$ can be attributed to $\mathrm{C}=\mathrm{C}$ stretching mode of the $\mathrm{sp}^{2}$ carbon skeletal network and/or to epoxy groups. The band at $1356 \mathrm{~cm}^{-1}$ is due to $\mathrm{C}-\mathrm{OH}$ stretching of $\mathrm{O}-\mathrm{H}$ groups, while the band at 1045 and at $1141 \mathrm{~cm}^{-1}$ can be also attributed to epoxy and alkoxy C-O groups, respectively.

Polyurethane (PU) is a polymer obtained after the polymerization of diisocyanate and polyol that contains $\mathrm{C}=\mathrm{O}$ and $-\mathrm{NH}$ groups (electron donating sites); these groups are able to form hydrogen bonds with graphene oxide during the complexation. The spectra of PU-GO-PVA sponge presented peaks at 1740 and $1060 \mathrm{~cm}^{-1}$ attributed to carboxyl and epoxy groups, respectively, at a lower intensity compared to the relative peaks of the spectra of GO, indicating the involvement of these groups in the composite synthesis. The peaks at $1543 \mathrm{~cm}^{-1}$ could be attributed to amide II formation after reaction of the carboxylic groups of GO with -NH groups of PU while the peaks at about $1453 \mathrm{~cm}^{-1}$ could be attributed to $-\mathrm{CH}_{3}$ groups of PVA indicating the covering [37-39].

The most significant spectra alterations for the GO-PU-PVA after the SA adsorption (GO-PU-PVA-SA sample), are the new bands appearing at 1260 and $1070 \mathrm{~cm}^{-1}$ in addition to the diminishing of the peaks at 1191, 1130 and $1740 \mathrm{~cm}^{-1}$ (carbonyl) absorption bands (Figure 2). The new band at $1440 \mathrm{~cm}^{-1}$ can be attributed to amide I formation due to interactions between the SA amines and the sponge carboxylates, causing the diminishing of the band at $1740 \mathrm{~cm}^{-1}$. The new band at $1260 \mathrm{~cm}^{-1}$, can be attributed to hydrogen bond interaction between the GO-PU-PVA carboxyl groups and the sulfones $/ \mathrm{O}=\mathrm{S}=\mathrm{O}$ groups of $\mathrm{SA}$ which are strong hydrogen-bond acceptors. It is obvious that the grafting of PU with extra carboxyl groups enhanced the SA adsorption owning to their reactions with the amines and the hydrogen bond with the sulfones $/ \mathrm{O}=\mathrm{S}=\mathrm{O}$ groups of the $\mathrm{SA}$. This was also reported for dorzolamine encapsulation to chitosan, as well as for pramipexole adsorption on activated carbon. 


\subsection{Synthesis Optimization}

The mass of the material retained in the sponge was initially studied, keeping its second mass at $0.04 \mathrm{~g}$. After selecting three different levels $(0.12,0.24$, and $0.32 \mathrm{~g})$, the procedure of the sponge preparation was followed. The sample preparation was performed in standard solutions with all three materials. From the results as presented in Figure 3, it seems that the mass of $0.12 \mathrm{~g}$ is more effective for the adsorption.

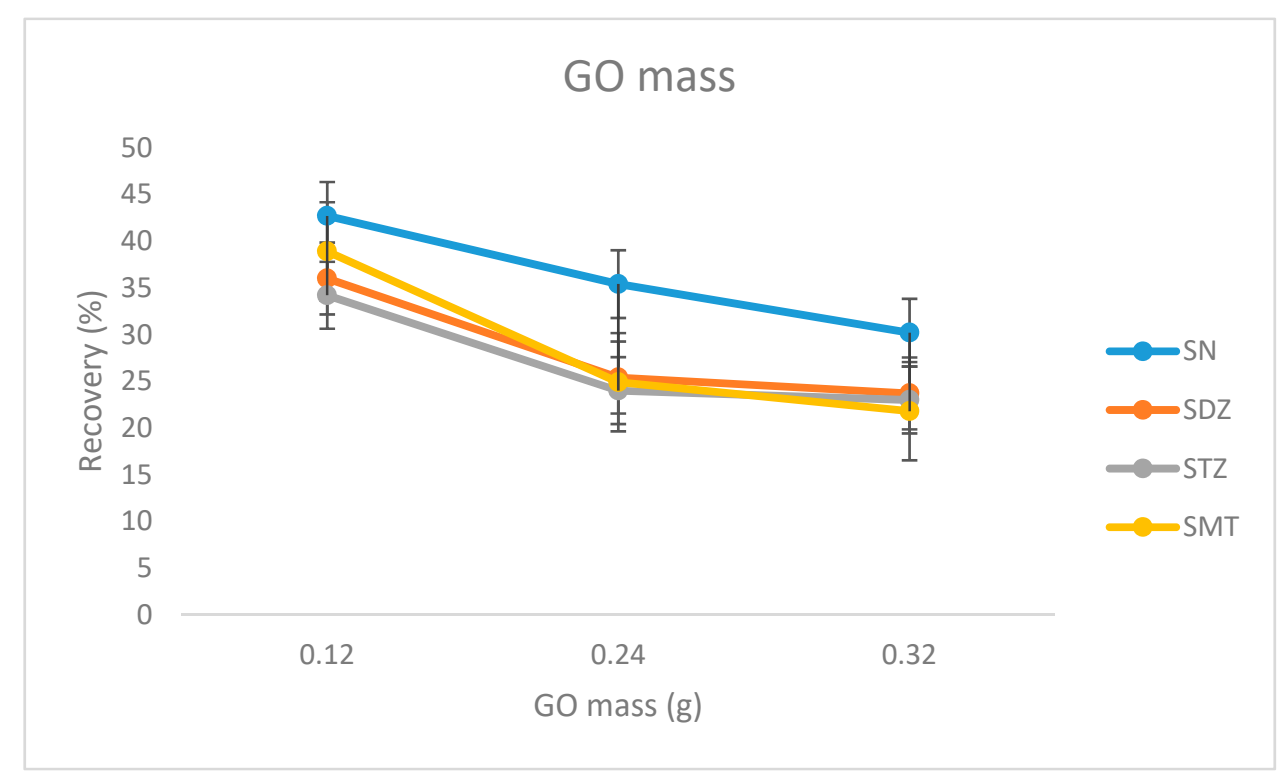

Figure 3. Effect of the graphene oxide (GO) mass on the adsorption efficiency of the sulfonamides.

The size of the sponge was optimized after the testing of two different sizes. Particularly $0.04 \mathrm{~g}$ and $0.07 \mathrm{~g}$ sponge were dipped in the dispersed solution. The results showed that the bigger sponge is sufficient to achieve the optimum adsorption.

For the PU-GO sponge formation, the GO molecules should be immobilized during its preparation. This is accomplished with the adding of a solvent like water or some polymer, of which polyvinyl alcohol (PVA) is more common due to its low cost. In the present research, two such solvents were tested, water and PVA. As shown in the results (Figure 4), PVA helps in the sample preparation procedure.

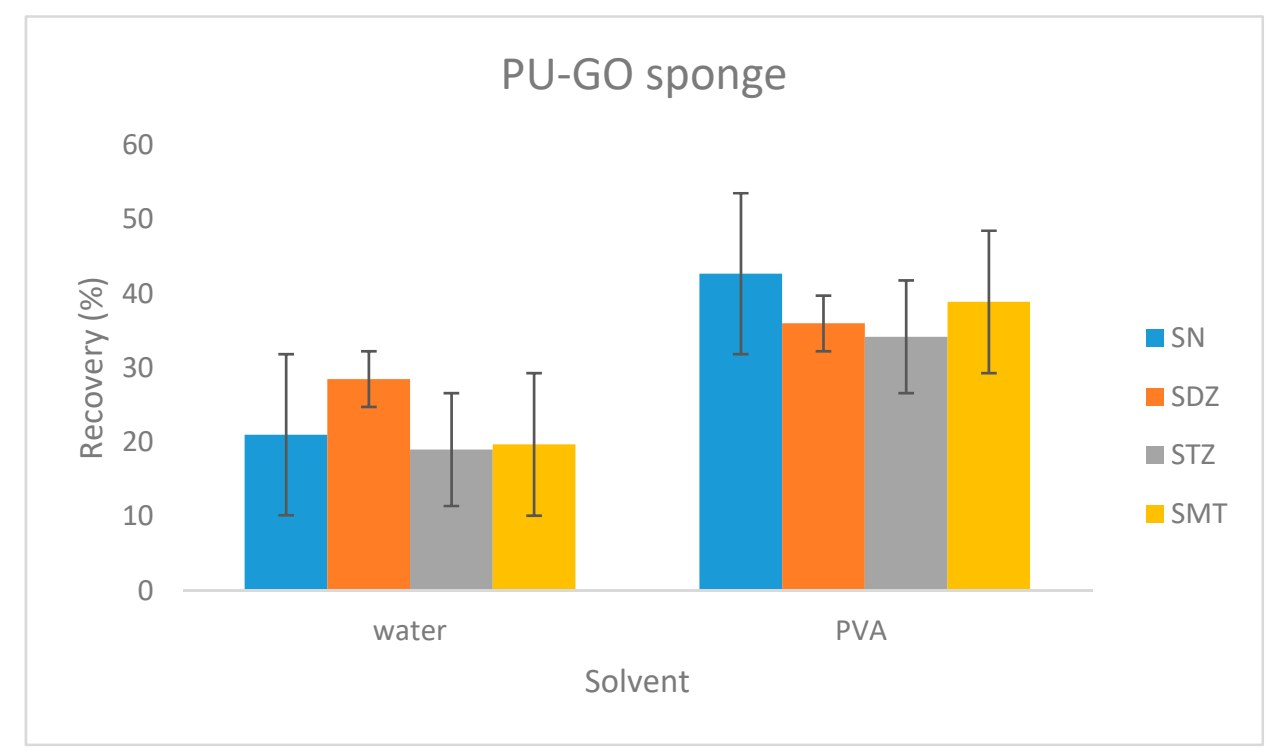

Figure 4. Effect of the solvent in the absolute recoveries of the four sulfonamides. 
Different solutions of $\mathrm{NH}_{3} / \mathrm{EtOH}$ containing $60 \mathrm{~mL}$ of the mixture were prepared in three different volume ratios (4:1,1:1 and 1:4) and were further applied in the functionalization of the GO-PU material. The results revealed that the quantity of $\mathrm{NH}_{3}$ was crucial to the absorption and that the volume ratio 4:1 achieved higher efficiency.

\subsection{Chromatography}

The target analytes were separated by gradient elution. Optimum gradient program was chosen as providing good analytes' resolution, at the shortest analysis. A typical chromatogram is shown in Figure 5. The retention times were observed at 6.345, 7.566, 8.748, and $12.899 \mathrm{~min}$ for SN, SDZ, STZ, and SMT respectively.

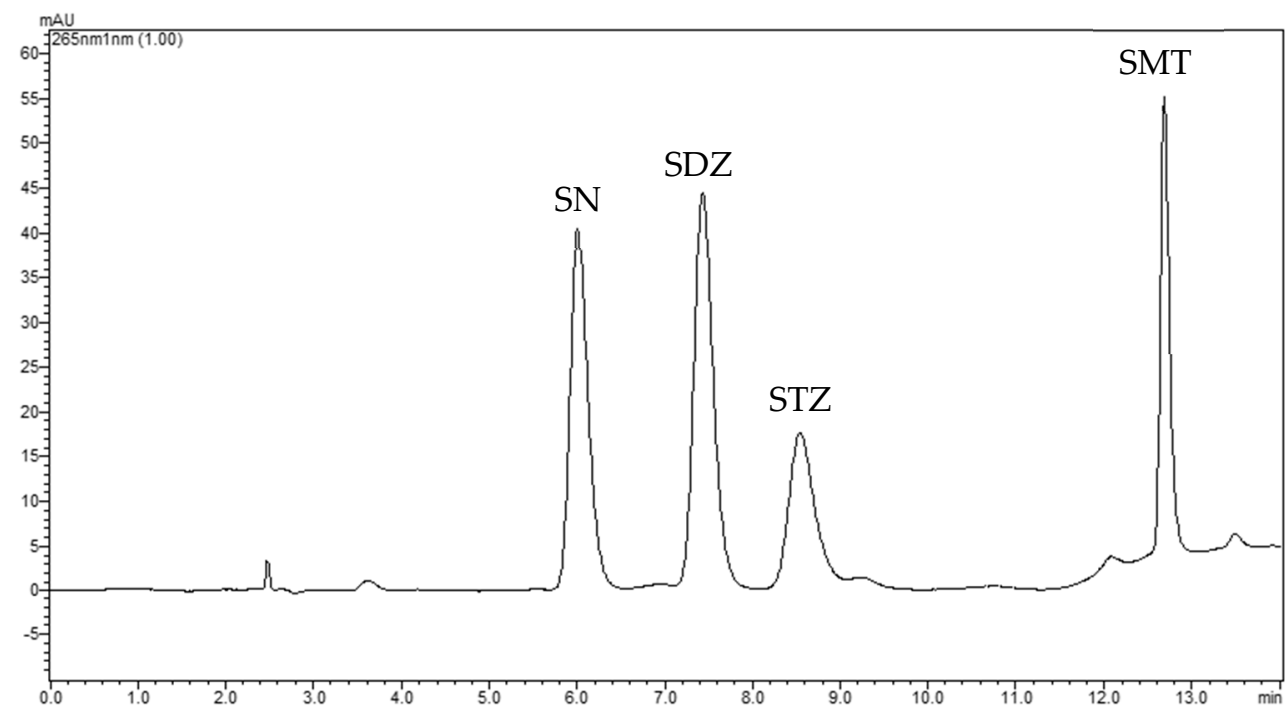

Figure 5. A typical HPLC chromatogram of standard solution of examined analytes at the concentration of $5 \mathrm{ng} \mu \mathrm{L}^{-1}$. Peaks are as follows: SN: $6.345 \mathrm{~min}$, SDZ: $7.566 \mathrm{~min}, \mathrm{STZ}: 8.748 \mathrm{~min}$, and SMT: $12.899 \mathrm{~min}$.

\subsection{Sample Preparation Optimization}

All initial optimization experiments were performed using standard solutions of sulfonamides. The optimum conditions established were further checked for their appropriateness to the milk matrix.

In the loading and elution step different methods were tested. Although stirring showed the best results in the tests with the standard solutions, as shown in Table 1 the extraction declined sharply when the milk samples were tested and the recovery rates ranged from 7 to $14 \%$. Thus, centrifugation in low rates was selected. Centrifugation at low rates had two purposes: (1) sufficient sample interaction with the material, and (2) preventing the adsorbent from escaping from the structure of the sponge. High centrifugation rates hindered the extraction process. With regards to sonication, GO particles were released from the sponge and sample handling was difficult.

Table 1. Effect of the loading/elution time and the extraction procedure on the efficiency of the method. (SN = sulfanilamide, $\mathrm{SDZ}=$ sulfadiazine, $\mathrm{STZ}=$ sulfathiazole, $\mathrm{SMT}=$ sulfamethizole $)$

\begin{tabular}{cccccc}
\hline \multirow{2}{*}{ Loading/Elution Time (min) } & \multicolumn{4}{c}{ Absolute Recovery Rates (R\%) } \\
\cline { 3 - 6 } & & SN & SDZ & STZ & SMT \\
\hline Rest & $15 / 15$ & 21.1 & 23.5 & 29.9 & 29.3 \\
\hline Sonication & $7 / 7$ & 15.6 & 21.2 & 29.7 & 33.7 \\
\hline Stirring & $15 / 15$ & 22.3 & 28.7 & 34.8 & 36.4 \\
\hline Centrifugation & $15 / 15$ & 30.9 & 24.0 & 27.6 & 29.6 \\
\hline
\end{tabular}


Additionally, the volume of the sample, the elution solvents, the size of the sponge, loading and elution time, and the $\mathrm{pH}$ were optimized. The extraction was conducted with two different volume samples (1.5 and $3 \mathrm{~g}$ ) that were spiked with the same amount of the target analytes. The results revealed a decrease in the extraction efficiency by increasing the volume of the sample.

With regards to the elution, methanol $(\mathrm{MeOH})$ and acetonitrile $(\mathrm{ACN})$ were tested both separately and in mixture. It is obvious from the results that the mixed solution increases the efficiency of the elution. In order to succeed better results, $1 \%$ acetic acid was added. The addition of acetic acid was successful and the optimum volume ratio for the $\mathrm{CH}_{3} \mathrm{COOH} / \mathrm{ACN} / \mathrm{MeOH}$ solution was 50:40:10.

As for the loading and elution time 10, 15, 20 min were tested. From the results it is observed that $10 \mathrm{~min}$ are not enough for the loading and the extraction of the target analytes. However, 15 and 20 min yielded similar results, and the shortest time was selected to reduce the process time.

The effect of the $\mathrm{pH}$ in the extraction efficiency was tested, adding $0.5 \mathrm{~mL}$ of buffer solution into

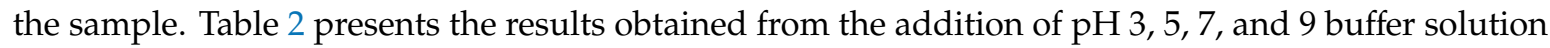
in milk sample. It is obvious from the results that the optimum $\mathrm{pH}$ is 5 , whereas lower or higher $\mathrm{pH}$ values results in decrease in the adsorption for all SAs.

Table 2. Effect of the $\mathrm{pH}$ on the adsorption efficiency of the four sulfonamides. ( $\mathrm{SN}=$ sulfanilamide, $\mathrm{SDZ}=$ sulfadiazine $\mathrm{STZ}=$ sulfathiazole, $\mathrm{SMT}=$ sulfamethizole). Optimum $\mathrm{pH}$ value is given in bold.

\begin{tabular}{ccccc}
\hline \multicolumn{5}{c}{ Absolute Recovery Rates (R\%) } \\
\hline $\mathbf{p H}$ & SN & SDZ & STZ & SMT \\
\hline 3 & 21.8 & 22.0 & 31.7 & 29.3 \\
\hline $\mathbf{5}$ & $\mathbf{2 2 . 2}$ & $\mathbf{2 7 . 5}$ & $\mathbf{3 6 . 1}$ & $\mathbf{3 1 . 7}$ \\
\hline 7 & 12.3 & 17.1 & 21.7 & 17.2 \\
\hline 9 & 15.0 & 22.0 & 27.9 & 19.0 \\
\hline
\end{tabular}

The proposed sample preparation protocol is very simple and rapid, with low consumption of organic solvents and very clean background signal. Figure 6 illustrates the simple pretreatment procedure. Typical chromatograms of a blank and a spiked milk sample are shown in Figure 7a,b. It is clear that the peaks of the substrate do not interfere with the analysis as they elute at different times.

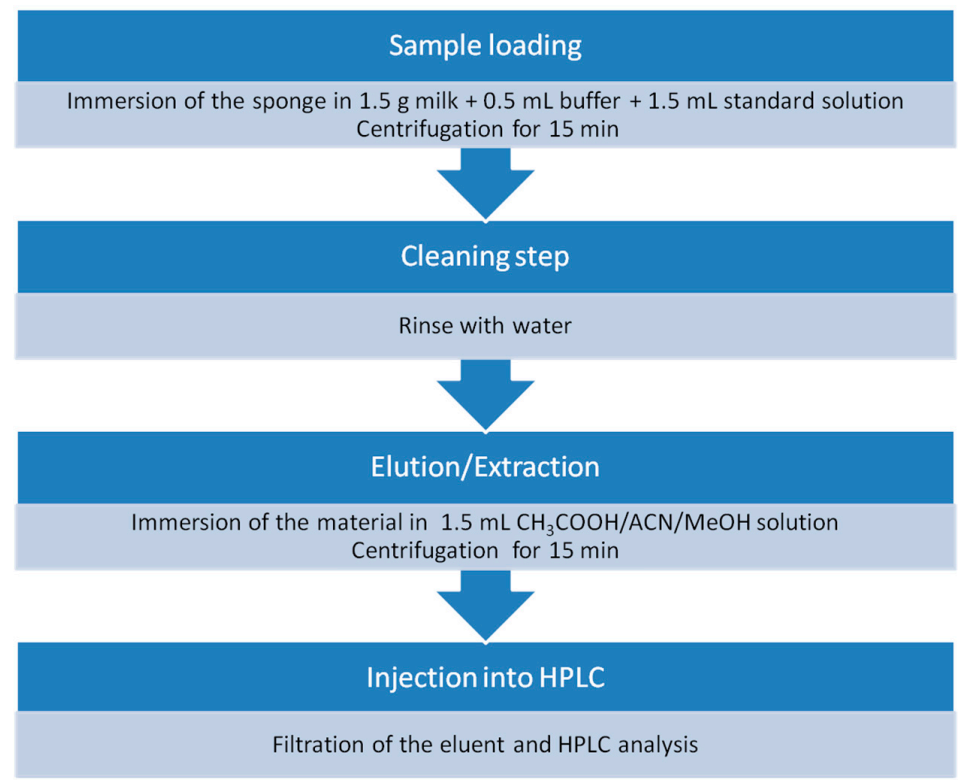

Figure 6. Steps of sample preparation procedure. 


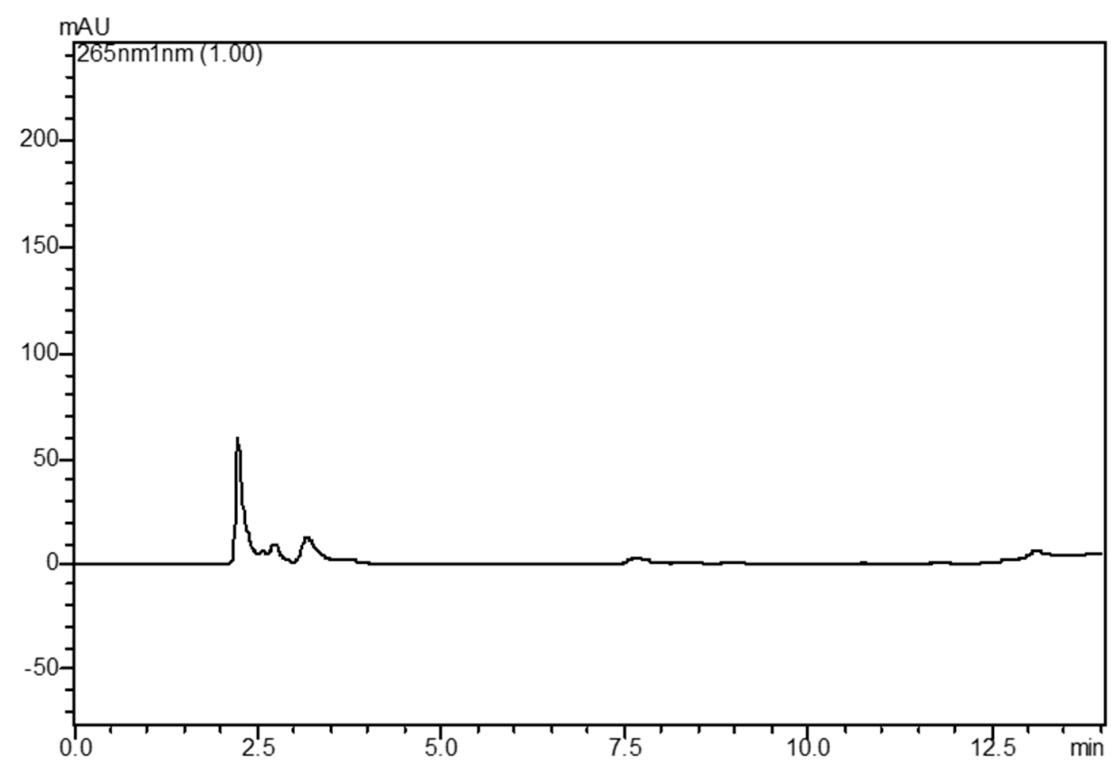

(a)

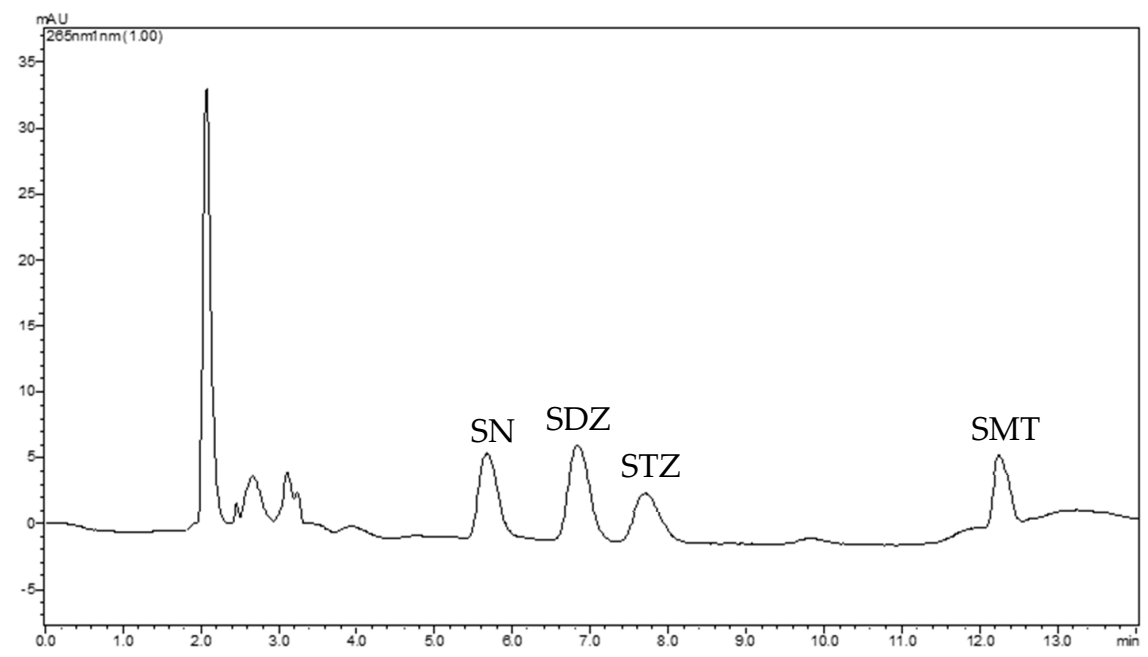

(b)

Figure 7. Chromatogram of (a) blank milk sample and (b) spiked milk sample at a concentration of $300 \mu \mathrm{g} \mathrm{kg}^{-1}$.

\subsection{Method Validation}

\subsubsection{Selectivity}

The good resolution between the chromatographic peaks of analytes and the absence of interferences in the spiked milk samples indicate that a good selectivity was achieved.

\subsubsection{Linearity and Sensitivity}

Standard solutions showed linearity for all of the target analytes within the range of 0.5 to $10 \mathrm{ng} \mu \mathrm{L}^{-1}$ and showed and good correlation coefficients (0.981-0.999). Moreover, calibration curves were constructed using fortified milk samples after sample preparation, and good coefficients of determination between 0.9969 and 0.999 were achieved over the examined range. (Table 3). Limit of quantification for all analytes in milk was $50 \mu \mathrm{g} \mathrm{kg}^{-1}$. 
Table 3. Linearity data in standard solutions and spiked milk samples. (SN = sulfanilamide, $\mathrm{SDZ}=$ sulfadiazine, $\mathrm{STZ}=$ sulfathiazole, $\mathrm{SMT}=$ sulfamethizole).

\begin{tabular}{ccc}
\hline Analytes & Calibration Curve & \multirow{2}{*}{ Coefficients of Determination $\mathbf{( R}^{2} \mathbf{)}$} \\
\cline { 1 - 2 } & Standard Solutions & 0.999 \\
\hline SN & $y=119367 x+366.66$ & 0.995 \\
\hline SDZ & $y=121371 x+27142$ & 0.999 \\
\hline STZ & $y=64281 x+16245$ & 0.981 \\
\hline SMT & $y=58218 x+13560$ & \\
\hline \multicolumn{3}{c}{ Milk } \\
\hline SDZ & $y=14785 x-1957.4$ & 0.996 \\
\hline STZ & $y=17012 x-3034.3$ & 0.998 \\
\hline SMT & $y=10182 x-2023.9$ & 0.991 \\
\hline
\end{tabular}

\subsubsection{Precision and Accuracy}

The precision of the method was based on within-day repeatability and between-day precision. The former was assessed by replicate $(n=4)$ measurements from a spiked milk sample at the MRL level for all examined sulfonamides. The recoveries of spiked samples were calculated by comparison of the peak area ratios for extracted compounds toward the values derived from spiked calibration curves. In Between-day reproducibility a triplicate determination was performed for a period of three days (Table 4). Precision and accuracy was determined at three concentration levels according to the 657/2002/EC decision [40].

Table 4. Precision and accuracy parameters of the method for the determination of sulfonamides in milk samples. $(\mathrm{SN}=$ sulfanilamide, $\mathrm{SDZ}=$ sulfadiazine, $\mathrm{STZ}=$ sulfathiazole, $\mathrm{SMT}=$ sulfamethizole $)$.

\begin{tabular}{|c|c|c|c|c|c|}
\hline \multirow{2}{*}{ Added Concentration $\left(\mu \mathrm{g} \mathrm{kg}^{-1}\right)$} & \multirow{2}{*}{ Analyte } & \multicolumn{2}{|c|}{ Intra-Day $n=4$} & \multicolumn{2}{|c|}{ Inter-Day $n=3 \times 3$} \\
\hline & & $\mathrm{R} \%$ & RSD & $\mathbf{R} \%$ & RSD \\
\hline \multirow{4}{*}{50} & $\mathrm{SN}$ & 98.2 & 7.6 & 97.6 & 7.1 \\
\hline & SDZ & 106.7 & 6.9 & 104.3 & 3.3 \\
\hline & STZ & 93.6 & 8.5 & 95.6 & 9.8 \\
\hline & SMT & 93.4 & 10.4 & 90.8 & 11.0 \\
\hline \multirow{4}{*}{100} & SN & 103.3 & 4.0 & 107.7 & 4.0 \\
\hline & SDZ & 112.1 & 10.8 & 105.3 & 0.4 \\
\hline & STZ & 96.8 & 11.0 & 90.2 & 10.9 \\
\hline & SMT & 92.8 & 11.8 & 97.6 & 12.4 \\
\hline \multirow{4}{*}{150} & $\mathrm{SN}$ & 100.2 & 10.4 & 102.4 & 7.6 \\
\hline & SDZ & 108.7 & 3.0 & 100.1 & 6.0 \\
\hline & STZ & 96.6 & 9.8 & 92.8 & 12.0 \\
\hline & SMT & 101.7 & 10.3 & 95.3 & 9.5 \\
\hline
\end{tabular}

\subsubsection{Decision Limit and Capability of Detection}

Decision limit $(\mathrm{CC} \alpha)$ is defined as "the limit at and above which it can be concluded with an error probability" and it was calculated after the analysis of 20 spiked milk samples at the MRLs of each compound. The decision limits CCa were $100.2 \mu \mathrm{g} \mathrm{kg}^{-1}$ for SN, $100.3 \mu \mathrm{g} \mathrm{kg}^{-1}$ for SDZ, $100.4 \mu \mathrm{g} \mathrm{kg}-1$ 
for STZ, and $\mu \mathrm{g} \mathrm{kg}^{-1}$ for 100.3 SMT. Capability of detection $(\mathrm{CCb})$ defined as "the smallest content of the substance that may be detected, identified, and/or quantified in a sample with an error probability of $b^{\prime \prime}$ and it was calculated after the spiking of 20 blank milk samples at the CCa level of each compound. The capability of detection (CCb) were $110.7 \mu \mathrm{g} \mathrm{kg}^{-1}$ for SN, $109.3 \mu \mathrm{g} \mathrm{kg}^{-1}$ for SDZ, $115.4 \mu \mathrm{g} \mathrm{kg}{ }^{-1}$ for STZ, and $114.3 \mu \mathrm{g} \mathrm{kg}^{-1}$ for SMT.

\subsection{Application to Real Samples}

The method was applied for the determination of the examined analytes in cow milk samples from local food stores. Five random samples of three different types of milk were collected and analyzed, including full-fat (3.5\%), semi-skimmed (1.5\%), and skimmed (0\%) milk. All analyzed samples were negative in the presence of examined analytes.

\subsection{Comparison with Other Methods}

The method described in this study was compared with previous analytical approaches for the determination of SAs in milk. The analysis' results are comparable with those attained by other methods, with fairly good recoveries and quite satisfactory sensitivity. Although it provides higher LODs and LOQs than previously reported methods, it is a less costly (no commercial SPE products are needed) and less time-consuming method with easy handling of sponge and does not require highly sophisticated equipment since no MS is used (Table 5).

Table 5. Performance of the presented method in comparison with previously reported analytical methods.

\begin{tabular}{|c|c|c|c|c|c|c|}
\hline Analytes & $\begin{array}{c}\text { Sample } \\
\text { Preparation }\end{array}$ & $\begin{array}{l}\text { Analytical } \\
\text { Technique }\end{array}$ & $\begin{array}{l}\text { Run Time } \\
(\mathrm{min})\end{array}$ & LOD-LOQ & $\begin{array}{c}\text { Recovery } \\
(\%)\end{array}$ & Ref \\
\hline 4SAs & MSPE & HPLC-AS & N/A & $\begin{array}{l}\text { LOD (ng/mL): } 2.0-2.5 \\
\text { LOQ (ng/mL): } 6.0-7.5\end{array}$ & 92-105 & [41] \\
\hline $\begin{array}{l}38 \text { veterinary } \\
\text { drugs }(18 \mathrm{SAs})\end{array}$ & SPE & UHPLC-ESI-MS/MS & 13.5 & $\begin{array}{l}\mathrm{CC} \alpha(\mu \mathrm{g} / \mathrm{kg}): 109-114 \text { (SAs) } \\
\mathrm{CC} \beta(\mu \mathrm{g} / \mathrm{kg}): 116-123 \text { (SAs) }\end{array}$ & $\begin{array}{l}87-119 \text { (all } \\
\text { analytes) }\end{array}$ & [42] \\
\hline 6SAs & SPE & HPLC-DAD & 15.3 & $\begin{array}{l}\text { LOD }(\mu \mathrm{g} / \mathrm{kg}): 1.9-13.3 \\
\text { LOQ }(\mu \mathrm{g} / \mathrm{kg}): 5.6-42.2\end{array}$ & N/A & [7] \\
\hline 9SAs & MSPE & HPLC-DAD & 35 & LOD $(\mu \mathrm{g} / \mathrm{L}): 7-14$ & $81.8-114.9$ & [27] \\
\hline $5 \mathrm{SAs}$ & MSPE & HPLC-UV & 8 & $\begin{array}{l}\text { LOD }(\mu \mathrm{g} / \mathrm{L}): 1.16-1.59 \\
\mathrm{LOQ}(\mu \mathrm{g} / \mathrm{L}): 3.52-4.81\end{array}$ & $62.0-104.3$ & [12] \\
\hline $\begin{array}{l}\text { SMZ, SIX and } \\
\text { SDMX }\end{array}$ & FPSE & HPLC-UV & 6.5 & $\begin{array}{l}\text { CC } \alpha(\mu \mathrm{g} / \mathrm{kg}): 114.4-116.5 \\
C C \beta(\mu \mathrm{g} / \mathrm{kg}): 104.1-118.5\end{array}$ & 93-107 & [11] \\
\hline 9 SAs & $\begin{array}{c}\text { GMeS } \\
\text { microextraction }\end{array}$ & HPLC-DAD & 30 & LOQ ( $\mu \mathrm{g} / \mathrm{kg}): 0.31-0.91$ & 90-105 & {$[28]$} \\
\hline 4 SAs & $\begin{array}{l}\text { PU-GO sponge } \\
\text { microextraction }\end{array}$ & HPLC-DAD & 14 & LOQ: $50(\mu \mathrm{g} / \mathrm{kg})$ & $90.2-112.1$ & $\begin{array}{l}\text { This } \\
\text { study }\end{array}$ \\
\hline
\end{tabular}

\section{Materials and Methods}

\subsection{Chemicals and Reagents}

Sulfathiazole (STZ), sulfamethizole (SMT), sulfadiazine (SDZ), and sulfanilamide (SN) were purchased from Sigma-Aldrich (Steinheim, Germany). HPLC grade acetonitrile and methanol obtained from Chem-Lab (Zedelgem, Belgium). Formic and acetic acid were of analytical grade and purchased from Chem-Lab (Zedelgem, Belgium) and Merck (Darmstadt, Germany) respectively. Ethanol, reagent grade (Chem-Lab, Zedelgem, Belgium) and ammonia, 25\% solution (PANREAC QUIMICA SA, Barcelona, Spain) were used for the sponge optimization. Polyvinyl alcohol high molecular weight solid, (PVA 98-99 hydrolized) was purchased from A Johnson Company (New Brunswick, NJ, USA).

Graphite was purchased from Sigma Aldrich (St. Louis, MO, USA). Double-deionized water was filtered with $0.45 \mu \mathrm{m}$ filter membrane before use. 
Milk samples were collected from local market (Thessaloniki, Greece). Different fresh milk types were analyzed including skimmed ( $0 \%$ fat), semi-skimmed (1.5\% fat), and full-fat milk ( $3.5 \%$ fat). All milk samples were kept refrigerated $\left(\right.$ at $\left.4{ }^{\circ} \mathrm{C}\right)$ until use.

\subsection{Instrumentation}

Chromatographic separation and analysis were carried out on a Shimadzu HPLC system coupled to a Diode Array Detector (DAD) (Kyoto, Japan), equipped with Rheodyne 7725i $20 \mu \mathrm{L}$ loop (Cotati, CA, USA). The system consisted of a Shimadzu LC-10 ADVP pump and a Shimadzu FCV-10ALVP solvent mixer (Kyoto, Japan). The chromatographic separation was achieved using a Merck-Lichrospher RP8e, $5 \mu \mathrm{m} 250 \times 4 \mathrm{~mm}$ analytical column (Darmstadt, Germany). Degassing of the mobile phase was performed by helium DGU-10B degassing unit by Shimadzu (Kyoto, Japan) directly in the solvent reservoirs. The system was controlled by Shimadzu LabSolutions software (Shimadzu, Kyoto, Japan) which was also used for the data acquisition and analysis.

A glass vacuum filtration apparatus obtained from Alltech Associates (Deerfield, IL, USA), was employed for the filtration of the solvents using cellulose nitrate $0.2 \mu \mathrm{m}$ membrane filters from Whatman (Maidstone, UK) prior to use. A Glasscol Vortexer (Terre Haute, IN, USA), an ultrasonic bath Transonic 460/H (Elma, Germany), a Reacti-Vap evaporator model from PIERCE (Rockford, IL, USA), and a Hermle centrifugation (Gosheim, Germany) were acquired for the sample preparation. Moreover, a 20-200 $\mu \mathrm{L}$ micropipette ISOLAB Laborgerate GmbH (Wertheim, Germany) was used for the preparation of the standard solutions.

XRD measurements were performed on a Philips PW1820 X-ray diffractometer. The Fourier Transform Infrared Spectra (FTIR) were measured on a Nicolet 560 (Thermo Fisher Scientific Inc., MA, USA) spectrometer.

\subsection{Chromatography}

The mobile phase consisted of water, containing $0.1 \%(v / v)$ formic acid (A), acetonitrile (B), and methanol (C). The analytes were separated following a gradient elution program, starting at 80:3:17 $(v / v / v)$, turning to $74: 6: 20(v / v / v)$ in the next $7.5 \mathrm{~min}$, kept isocratic for $2.5 \mathrm{~min}$, and finally changing to $50: 10: 40(v / v / v)$ in the last three minutes. The flow rate was set at $1.0 \mathrm{~mL} \mathrm{~min}^{-1}$, while monitoring of the analytes was set at $265 \mathrm{~nm}$.

\subsection{Functionalization of Sponges}

A commercially available polyurethane sponge was cut into cubes, immersed into ethanol/water solution, and placed in an ultrasonic bath for $20 \mathrm{~min}$. The sponge was left at room temperature to dry and then it was dipped in a GO mixture for $24 \mathrm{~h}$ to be stirred mechanically. The mixture was prepared by the addition of $0.12 \mathrm{~g} \mathrm{GO}$ in $60 \mathrm{~mL} \mathrm{NH}_{3} / \mathrm{EtOH}$ solution $(4: 1, v / v)$. When mechanical stirring was completed, the sponge was left to dry in room temperature. Subsequently it was rinsed with water and PVA solvent was added as a final step. The PU-GO sponge is shown in Figure 8. 


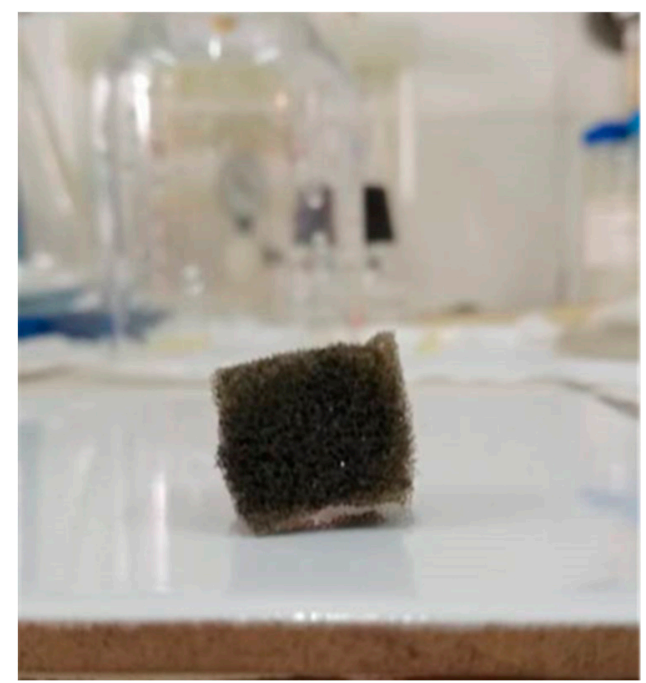

Figure 8. Image of the polyurethane-graphene oxide (PU-GO) sponge.

\subsection{Sample Preparation}

In the present study, defatted bovine milk was used and the proteins' precipitation was achieved by adding $3 \mathrm{~mL}$ of $\mathrm{ACN}$ in $1.5 \mathrm{~g}$ of milk. The $\mathrm{pH}$ was adjusted to 5.0 by using $0.5 \mathrm{~mL}$ of buffer solution $\left(70 \% \mathrm{CH}_{3} \mathrm{COONa} 0.2 \mathrm{M} / 30 \% \mathrm{CH}_{3} \mathrm{COOH} 0.2 \mathrm{M}\right.$ ). The sponge was initially placed in a vial containing $1.5 \mathrm{~g}$ of milk and the system was centrifuged at low rpm for $15 \mathrm{~min}$. The material was rinsed with deionized water and then squeezed to wash the water away. Subsequently, $1.5 \mathrm{~mL}$ of $1 \%$ $\mathrm{CH}_{3} \mathrm{COOH} / \mathrm{ACN} / \mathrm{MeOH}$ solution $(50: 40: 10 \mathrm{v} / \mathrm{v} / \mathrm{v})$ was added to the sponge and the analytes were eluted by centrifugation at low rpm for $15 \mathrm{~min}$. The eluent was filtered and injected in the HPLC column.

In the case of fat containing milk samples, centrifugation was applied for fat removal prior to deproteinization. Moreover, sample preconcentration was applied by evaporation of elution solvent prior to HPLC analysis and reconstitution to $100 \mu \mathrm{L}$ when necessary and in order to reach the legislation demands.

\subsection{Standard Solution Preparation}

For the chromatographic analysis, stock standard solutions of each analyte were prepared at a concentration of $100 \mathrm{ng} \mu \mathrm{L}^{-1}$ using a solvent with the same composition as the mobile phase. Stock standard solutions were stable for six months at $4{ }^{\circ} \mathrm{C}$, while working standards were prepared on a daily basis. The calibration curves were constructed by the use of solutions being prepared at concentrations of $0.5-10 \mathrm{ng} \mu \mathrm{L}^{-1}$.

\subsection{Method Validation}

The method was validated using spiked samples, under the optimal conditions, in terms of linearity, sensitivity, selectivity, and precision (repeatability and between-day precision), decision limit (CCa), decision capability (CCb), and stability according to the European Decision 657/2002/EC [40].

Linearity was studied by triplicate analysis of working standard solutions at concentration levels between $0.5 \mathrm{ng} \mu \mathrm{L}^{-1}$ to $10 \mathrm{ng} \mu \mathrm{L}^{-1}$. In milk, linearity was examined by triplicate analysis of spiked samples within the range of $50 \mu \mathrm{g} \mathrm{kg}^{-1}-10,000 \mu \mathrm{g} \mathrm{kg}{ }^{-1}$ and calibration curves were calculated. Limits of detection (LOD) and quantification (LOQ) were considered as the concentration giving a signal to noise ratio of 3 and 10, respectively. The selectivity of the method was proved by the absence of interference of endogenous compounds in the analysis of blank milk samples.

Precision and accuracy were calculated by analyzing spiked samples at the concentration levels of $50 \mu \mathrm{g} \mathrm{kg}^{-1}, 100 \mu \mathrm{g} \mathrm{kg}{ }^{-1}$ and $150 \mu \mathrm{g} \mathrm{kg}^{-1}$, which correspond to the $\frac{1}{2} \mathrm{MRL}$, MRL, and $1 \frac{1}{2}$ MRL of sulfonamides [6]. Within-day repeatability was examined by 4 measurements at the above concentration 
levels. Between-day precision was assessed by performing triplicate analysis at the same concentration levels in three days. The relative recovery was calculated using the formula of the percentage of the ratio of the analyte mass that was found in the spiked sample, to the spiked mass.

Decision limit (CCa) was calculated using the equation $\mathrm{CCa}=\mathrm{MRL}+1.64 \times \mathrm{SD}$, where $\mathrm{SD}$ is the standard deviation of the duplicate measurements of twenty milk samples spiked at MRL concentrations of each analyte. Decision capability $(\mathrm{CCb})$ was calculated using the equation $\mathrm{CCb}=\mathrm{CCa}+1.64 \times \mathrm{SD}$, with the SD being the standard deviation of the duplicate measurements of twenty milk samples spiked at CCa concentrations of each sulfonamide.

\section{Conclusions}

In the present study a new novel material was presented. Particularly, a PU-GO sponge was prepared, taking advantage of the unique properties of GO combined with the characteristics of the common PU sponge. This novel material was applied for the sample preparation of milk samples for the determination of sulfonamides prior to HPLC. The easy preparation of the material and the extremely fast, simple, and green sample preparation procedure make the proposed method suitable for the analysis of a complex matrix such as milk. It is the first time that the PU-GO sponge was applied for the determination of sulfonamides in milk samples. Furthermore, it is a less costly and time-consuming method and requires less equipment than previously reported methods.

Author Contributions: Conceptualization, V.F.S. and E.A.D.; methodology, software, validation, formal analysis, investigation, resources, data curation, V.F.S., E.A.D. and M.M. Writing-original draft preparation, V.F.S., E.A.D. and M.M. writing-review and editing, V.F.S. and E.A.D.; supervision, project administration, V.F.S. and E.A.D.

Funding: This research received no external funding.

Conflicts of Interest: The authors declare that there are no conflicts of interest.

\section{References}

1. Samanidou, V.F.; Tolika, E.P.; Papadoyannis, I.N. Development and validation of an HPLC confirmatory method for the residue analysis of four sulfonamides in cow's milk according to the European Union decision 2002/657/EC. J. Liq. Chromatogr. Relat. Technol. 2008, 31, 1358-1372. [CrossRef]

2. Arroyo-Manzanares, N.; Gámiz-Gracia, L.; García-Campaña, A.M. Alternative sample treatments for the determination of sulfonamides in milk by HPLC with fluorescence detection. Food Chem. 2014, 143, 459-464. [CrossRef] [PubMed]

3. Karageorgou, E.; Christoforidou, S.; Ioannidou, M.; Psomas, E.; Samouris, G. Detection of $\beta$-lactams and chloramphenicol residues in raw milk-development and application of an HPLC-DAD method in comparison with microbial inhibition assays. Foods 2018, 7, 82. [CrossRef]

4. Bitas, D.; Kabir, A.; Locatelli, M.; Samanidou, V. Food sample preparation for the determination of sulfonamides by high-performance liquid chromatography: State-of-the-art. Separations 2018, 5, 31. [CrossRef]

5. Dmitrienko, S.G.; Kochuk, E.V.; Apyari, V.V.; Tolmacheva, V.V.; Zolotov, Y.A. Recent advances in sample preparation techniques and methods of sulfonamides detection-A review. Anal. Chim. Acta 2014, 850, 6-25. [CrossRef]

6. Commission Regulation (EU) Commission Regulation (EU) No 37/2010. Off. J. Eur. Union 2010, L 15, 1-72.

7. Kechagia, M.; Samanidou, V.; Kabir, A.; Furton, K.G. One-pot synthesis of a multi-template molecularly imprinted polymer for the extraction of six sulfonamide residues from milk before high-performance liquid chromatography with diode array detection. Sep. Sci. 2018, 41, 723-741. [CrossRef]

8. Wang, S.; Zhang, H.Y.; Wang, L.; Duan, Z.J.; Kennedy, I. Analysis of sulphonamide residues in edible animal products: A review. Food Addit. Contam. 2006, 23, 362-384. [CrossRef]

9. Zotou, A.; Vasiliadou, C. LC of sulfonamide residues in poultry muscle and eggs extracts using fluorescence pre-column derivatization and monolithic silica column. J. Sep. Sci. 2010, 33, 11-22. [CrossRef]

10. McClure, E.L.; Wong, C.S. Solid phase microextraction of macrolide, trimethoprim, and sulfonamide antibiotics in wastewaters. J. Chromatogr. A 2007, 1169, 53-62. [CrossRef] 
11. Karageorgou, E.; Manousi, N.; Samanidou, V.; Kabir, A.; Furton, K.G. Fabric phase sorptive extraction for the fast isolation of sulfonamides residues from raw milk followed by high performance liquid chromatography with ultraviolet detection. Food Chem. 2016, 196, 428-436. [CrossRef]

12. Li, Y.; Wu, X.; Li, Z.; Zhong, S.; Wang, W.; Wang, A.; Chen, J. Fabrication of $\mathrm{CoFe}_{2} \mathrm{O}_{4}$-graphene nanocomposite and its application in the magnetic solid phase extraction of sulfonamides from milk samples. Talanta 2015, 144, 1279-1286. [CrossRef]

13. Garrido Frenich, A.; del Mar Aguilera-Luiz, M.; Martínez Vidal, J.L.; Romero-González, R. Comparison of several extraction techniques for multiclass analysis of veterinary drugs in eggs using ultra-high pressure liquid chromatography-tandem mass spectrometry. Anal. Chim. Acta 2010, 661, 150-160. [CrossRef]

14. Maggira, M.; Samanidou, V. QuEChERS: The dispersive methodology approach for complex matrices. J. Chromatogr. Sep. Tech. 2018, 9. [CrossRef]

15. Yan, H.; Sun, N.; Liu, S.; Row, K.H.; Song, Y. Miniaturized graphene-based pipette tip extraction coupled with liquid chromatography for the determination of sulfonamide residues in bovine milk. Food Chem. 2014, 158, 239-244. [CrossRef]

16. Wu, L.; Yu, L.; Ding, X.; Li, P.; Dai, X.; Chen, X.; Zhou, H.; Bai, Y.; Ding, J. Magnetic solid-phase extraction based on graphene oxide for the determination of lignans in sesame oil. Food Chem. 2017, 217, 320-325. [CrossRef]

17. Liu, Q.; Shi, J.; Zeng, L.; Wang, T.; Cai, Y.; Jiang, G. Evaluation of graphene as an advantageous adsorbent for solid-phase extraction with chlorophenols as model analytes. J. Chromatogr. A 2011, 1218, 197-204. [CrossRef]

18. Wang, X.; Liu, B.; Lu, Q.; Qu, Q. Graphene-based materials: Fabrication and application for adsorption in analytical chemistry. J. Chromatogr. A 2014, 1362, 1-15. [CrossRef]

19. Liu, Q.; Shi, J.; Sun, J.; Wang, T.; Zeng, L.; Jiang, G. Graphene and graphene oxide sheets supported on silica as versatile and high-performance adsorbents for solid-phase extraction. Angew. Chem. Int. Ed. 2011, 50, 5913-5917. [CrossRef]

20. Fumes, B.H.; Silva, M.R.; Andrade, F.N.; Nazario, C.E.D.; Lanças, F.M. Recent advances and future trends in new materials for sample preparation. TrAC Trends Anal. Chem. 2015, 71, 9-25. [CrossRef]

21. Maggira, M.; Samanidou, V.F. Graphene based materials in sample preparation prior to HPLC analysis and their applications. In High Performance Liquid Chromatography, Types, Parameters Applications; Ivan, L., Ed.; Nova Science Publishers, Inc.: Suite N Hauppauge, NY, USA, 2018.

22. Guan, W.; Li, Z.; Zhang, H.; Hong, H.; Rebeyev, N.; Ye, Y.; Ma, Y. Amine modified graphene as reversed-dispersive solid phase extraction materials combined with liquid chromatography-tandem mass spectrometry for pesticide multi-residue analysis in oil crops. J. Chromatogr. A 2013, 1286, 1-8. [CrossRef]

23. Huang, K.J.; Yu, S.; Li, J.; Wu, Z.W.; Wei, C.Y. Extraction of neurotransmitters from rat brain using graphene as a solid-phase sorbent, and their fluorescent detection by HPLC. Microchim. Acta 2012, 176, 327-335. [CrossRef]

24. Zhao, G.; Song, S.; Wang, C.; Wu, Q.; Wang, Z. Determination of triazine herbicides in environmental water samples by high-performance liquid chromatography using graphene-coated magnetic nanoparticles as adsorbent. Anal. Chim. Acta 2011, 708, 155-159. [CrossRef]

25. Wu, Q.; Liu, M.; Ma, X.; Wang, W.; Wang, C.; Zang, X.; Wang, Z. Extraction of phthalate esters from water and beverages using a graphene-based magnetic nanocomposite prior to their determination by HPLC. Microchim. Acta 2012, 177, 23-30. [CrossRef]

26. Zhang, X.; Niu, J.; Zhang, X.; Xiao, R.; Lu, M.; Cai, Z. Graphene oxide-SiO ${ }_{2}$ nanocomposite as the adsorbent for extraction and preconcentration of plant hormones for HPLC analysis. J. Chromatogr. B Anal. Technol. Biomed. Life Sci. 2017, 1046, 58-64. [CrossRef]

27. Ibarra, I.S.; Miranda, J.M.; Rodriguez, J.A.; Nebot, C.; Cepeda, A. Magnetic solid phase extraction followed by high-performance liquid chromatography for the determination of sulfonamides in milk samples. Food Chem. 2014, 157, 511-517. [CrossRef]

28. Chatzimitakos, T.; Samanidou, V.; Stalikas, C.D. Graphene-functionalized melamine sponges for microextraction of sulfonamides from food and environmental samples. J. Chromatogr. A 2017, 1522, 1-8. [CrossRef]

29. Wu, Q.; Zhao, G.; Feng, C.; Wang, C.; Wang, Z. Preparation of a graphene-based magnetic nanocomposite for the extraction of carbamate pesticides from environmental water samples. J. Chromatogr. A 2011, 1218, 7936-7942. [CrossRef] 
30. Su, C.; Yang, H.; Song, S.; Lu, B.; Chen, R. A magnetic superhydrophilic/oleophobic sponge for continuous oil-water separation. Chem. Eng. J. 2017, 309, 366-371. [CrossRef]

31. Su, C.; Yang, H.; Zhao, H.; Liu, Y.; Chen, R. Recyclable and biodegradable superhydrophobic and superoleophilic chitosan sponge for the effective removal of oily pollutants from water. Chem. Eng. J. 2017, 330, 423-432. [CrossRef]

32. Meng, H.; Yan, T.; Yu, J.; Jiao, F. Super-hydrophobic and super-lipophilic functionalized graphene oxide/polyurethane sponge applied for oil/water separation. Chin. J. Chem. Eng. 2018, 26, 957-963. [CrossRef]

33. Sheng, C.; Wenting, B.; Shijian, T.; Yuechuan, W. Electrochromic behaviors of poly (3-n-octyloxythiophene). Polymer (Guildf). 2008, 1-6.

34. Kyzas, G.Z.; Travlou, N.A.; Kyzas, G.Z.; Lazaridis, N.K.; Deliyanni, E.A. Functionalization of graphite oxide with magnetic chitosan for the preparation of a nanocomposite dye. Functionalization of graphite oxide with magnetic chitosan for the preparation of a nanocomposite dye adsorbent. Langmuir 2015, 29, 1657-1668.

35. Travlou, N.A.; Kyzas, G.Z.; Lazaridis, N.K.; Deliyanni, E.A. Graphite oxide/chitosan composite for reactive dye removal. Chem. Eng. J. 2013, 217, 256-265. [CrossRef]

36. Istanbullu, H.; Ahmed, S.; Sheraz, M.A.; Rehman, I. ur Development and characterization of novel polyurethane films impregnated with tolfenamic acid for therapeutic applications. Biomed Res. Int. 2013, 2013, 1-8. [CrossRef]

37. Zhou, S.; Hao, G.; Zhou, X.; Jiang, W.; Wang, T.; Zhang, N.; Yu, L. One-pot synthesis of robust superhydrophobic, functionalized graphene/polyurethane sponge for effective continuous oil-water separation. Chem. Eng. J. 2016, 302, 155-162. [CrossRef]

38. Xu, Y.; Hong, W.; Bai, H.; Li, C.; Shi, G. Strong and ductile poly(vinyl alcohol)/graphene oxide composite films with a layered structure. Carbon N. Y. 2009, 47, 3538-3543. [CrossRef]

39. Liang, J.; Huang, Y.; Zhang, L.; Wang, Y.; Ma, Y.; Cuo, T.; Chen, Y. Molecular-level dispersion of graphene into poly(vinyl alcohol) and effective reinforcement of their nanocomposites. Adv. Funct. Mater. 2009, 19, 2297-2302. [CrossRef]

40. Commission Decision, 2002/657/EC. 2002, pp. 8-36. Available online: https://eur-lex.europa.eu/legal-content/ EN/ALL/?uri=CELEX\%3A32002D0657 (accessed on 31 May 2019).

41. Tolmacheva, V.V.; Apyari, V.V.; Furletov, A.A.; Dmitrienko, S.G.; Zolotov, Y.A. Facile synthesis of magnetic hypercrosslinked polystyrene and its application in the magnetic solid-phase extraction of sulfonamides from water and milk samples before their HPLC determination. Talanta 2016, 152, 203-210. [CrossRef]

42. Hou, X.; Chen, G.; Zhu, L.; Yang, T.; Zhao, J.; Wang, L.; Wu, Y. Development and validation of an ultra high performance liquid chromatography tandem mass spectrometry method for simultaneous determination of sulfonamides, quinolones and benzimidazoles in bovine milk. J. Chromatogr. B 2014, 962, 20-29. [CrossRef]

Sample Availability: Samples of the compounds are not available from the authors.

(C) 2019 by the authors. Licensee MDPI, Basel, Switzerland. This article is an open access article distributed under the terms and conditions of the Creative Commons Attribution (CC BY) license (http://creativecommons.org/licenses/by/4.0/). 